\title{
Identification of Genetic Variations in CBL, SORBS1, CRK, and $R H O Q$, Key Modulators in the CAP/TC10 Pathway of Insulin Signal Transduction, and Their Association with Type 2 Diabetes Mellitus in the Korean Population
}

\author{
Kyung-Won Hong ${ }^{1}$, Hyun-Seok Jin ${ }^{1}$, Ji-Eun \\ $\mathrm{Lim}^{1}$, Min Jin $\mathrm{Go}^{2}$, Jong-Young Lee ${ }^{2}$, Sue-Yun \\ Hwang $^{3}$, Hun Kuk Park ${ }^{1}$ and Bermseok $\mathrm{Oh}^{1 *}$ \\ ${ }^{1}$ Department of Biomedical Engineering, School of Me- \\ dicine, Kyung Hee University, Seoul 130-701, Korea, \\ ${ }^{2}$ Center for Genome Science, National Institute of \\ Health, Seoul 122-701, Korea, ${ }^{3}$ Graduate School of \\ Informatics and Biotechnology, Hankyung National \\ University, Ansung 456-749, Korea
}

\begin{abstract}
Recent evidence has strongly suggested that the CAP/TC10 pathway is involved in the trafficking, docking, and fusion of vesicles containing the insulin-responsive glucose transporter Glut4 to the plasma membrane. However, little is known about how the genes employed in the CAP/TC10 pathway are associated with the development of type 2 diabetes mellitus. In this study, we sequenced 4 genes of the CAP/TC10 pathway [SORBS1,CBL, CRK, and RHOQ] in 24 individuals to identify genetic variations in these loci. A total of 48 sequence variants were identified, including 23 novel variations. To investigate the possible association with type 2 diabetes mellitus, 3 single nucleotide polymorphisms from SORBS1, 3 from $C B L$, and 4 from $R H O Q$ were genotyped in 1122 Korean type 2 diabetic patients and 1138 nondiabetic controls. Using logistic regression analysis, 1 significant association between SNP rs1376405 in $R H O Q$ and type 2 diabetes mellitus [OR $=8.714$ (C.I. 1.714-44.29), $\mathrm{p}=0.009$ ] was found in the recessive model. Our data demonstrate a positive association of the RHOQ gene in the CAP/TC10 pathway with T2DM in the Korean population.
\end{abstract}

Keywords: CAP/TC10, Glut 4, insulin, SNP, type 2 diabetes mellitus

*Corresponding author: E-mail ohbs@khu.ac.kr Tel +82-2-961-0617, Fax +82-2-961-5515 Accepted 2 June 2009

\section{Introduction}

During recent years, major advances have been made in our understanding of insulin actions. In the cell, the recognition of insulin by insulin receptor instigates phosphorylation of several intracellular substrates, such as the insulin receptor substrates (IRS1-4) (White and Yenush, 1998), calcineurin B-like protein 1 (Cbl1) (Ribon and Saltiel, 1997), Src homology 2 domain-containing transforming protein (Shc) (Sasaoka et al., 1994), SH2B adaptor protein 2 (SH2B2) (Liu et al., 2002), and p60 ${ }^{\mathrm{DOK}}$ (Noguchi et al., 1999). Defects in genes involved in the insulin signaling pathway are linked to the pathogenesis of type II diabetes mellitus (T2DM) (Zierath and Wallberg-Henriksson, 2002).

In the CAP/TC10 pathway, the insulin receptor recruits and phosphorylates $\mathrm{Cbl}$ proteins through an intermediary adaptor protein called SH2B2 (Liu, et al., 2002). Binding of the $\mathrm{SH} 2$ domain of SH2B2 to the phosphorylated insulin receptor facilitates phosphorylation of $\mathrm{SH} 2 \mathrm{~B} 2$, which then serves as a docking site for $\mathrm{Cbl}(\mathrm{Hu}$ and Hubbard, 2005). Another adaptor protein, termed sorbin, and $\mathrm{SH} 2$ domain-containing 1 (SORBS1), which is a human homolog of Cbl-associated protein (CAP), are involved in the targeting of $\mathrm{Cbl}$ to lipid raft microdomains (Ribon et al., 1998). Upon phosphorylation of Cbl, the Cbl/CAP complex provides docking sites for the recruitment of the adaptor protein CRKII and the guanyl nucleotide exchange factor C3G (Baumann et al., 2000; Ribon et al., 1996). Recruitment of C3G results in the activation of the small GTP-binding TC10 (protein product of the RHOQ gene). Activation of TC10 results in cytoskeletal rearrangements that are needed to facilitate Glut4 translocation upon insulin signaling as well as insulin-stimulated glucose uptake (Chiang et al., 2001). A recent study of streptozotocin-induced diabetic animals showed that $\mathrm{Cbl}$ and SORBS1 gene expression was significantly reduced and that the activation of TC10 was also abridged (Gupte and Mora, 2006). In spite of the pivotal role of the CAP/TC10 pathway in skeletal muscle and adipose tissue, the association of effector genes with T2DM has not been elucidated well. In the present report, we investigated the genetic var- 
iations of 4 genes encoding major components of the CAP/TC10 pathway-SORBS1, CBL, CRK, and RHOQand analyzed the association of their genetic variations with T2DM.

\section{Methods}

\section{Subjects and measurements}

We studied 1,122 type 2 diabetic cases (586 men and 536 women; age $56.2 \pm 8.80$ years (mean $\pm S D$ ), BMI $25.4 \pm 3.31 \mathrm{~kg} / \mathrm{m}^{2}$ ) and 1,138 nondiabetic controls (516 men and 622 women; age $64.2 \pm 2.87$ years, BMl 23.7 $\pm 3.7 \mathrm{~kg} / \mathrm{m}^{2}$ ). Diabetic patients were recruited from a Korean prospective community cohort study (AnsungAnsan) according to WHO criteria. Nondiabetic controls had no history of diabetes and had fasting plasma glucose levels less than $6.1 \mathrm{mmol} / \mathrm{L}$ and hemoglobin A1c (HbA1c) levels less than $5.8 \%$. The study was approved by the institutional review board of the Korean National Institute of Health. Written informed consent was obtained from all subjects. The clinical characteristics of subjects are shown in Table 1.

\section{Sequence determination of the human CAP/TC10 pathway genes}

We sequenced all exons, including exon-intron boundaries, and the promoter region (approximately $1.5 \mathrm{~kb}$ ) to discover single nucleotide polymorphisms (SNPs) in 24 Korean DNA samples using the ABI PRISM 3730 DNA analyzer (Applied Biosystems, Foster City, CA, USA). Twenty-eight primer sets for the amplification and sequencing analysis were designed based on sequence information from GenBank. Detailed description about primers is available in Supplementary Table 1. Individual sequence variants were verified on chromatograms.

\section{Genotyping}

The 10 SNPs were selected for genotyping based on haplotype tagging and minor allele frequency $(>0.5 \%)$. SNPs were genotyped using amplifying primers and probes designed for TaqMan (Livak, 1999). The Primer Express (Applied Biosystems) program was used to design both the PCR primers and the MGB TaqMan probes. Information regarding primers and probes is available in Supplementary Table 2. The detailed experimental procedures can be found in Park et al. (2006).

Table 1. Clinical characteristics of study subjects

\begin{tabular}{|c|c|c|c|c|c|c|c|}
\hline \multirow{2}{*}{ Variables } & \multirow{2}{*}{ Abbreviation } & \multicolumn{3}{|c|}{ Control } & \multicolumn{3}{|c|}{ Case } \\
\hline & & $\mathrm{N}$ & Mean & Std & $\mathrm{N}$ & Mean & Std \\
\hline \multicolumn{8}{|l|}{ Demographic variables } \\
\hline Age (yrs) & & 1,138 & 64.237 & 2.873 & 1,122 & $56.200^{\mathrm{a}}$ & 8.800 \\
\hline Onset (yrs) & & & & & 577 & 50.500 & 9.390 \\
\hline Duration (mths) & & & & & 577 & 82.200 & 83.000 \\
\hline Sex (men/women) & & \multicolumn{3}{|c|}{$516(45.34) / 622(54.66)$} & \multicolumn{3}{|c|}{$586(52.2) / 536(47.8)^{\mathrm{a}}$} \\
\hline \multicolumn{8}{|l|}{ Obesity index } \\
\hline Body mass index $\left(\mathrm{kg} / \mathrm{m}^{2}\right)$ & BMI & 1,138 & 23.660 & 3.143 & 1,121 & $25.400^{\mathrm{a}}$ & 3.140 \\
\hline Waist-to-hip ratio & WHR & 1,137 & 0.913 & 0.066 & 1,121 & 0.920 & 0.070 \\
\hline \multicolumn{8}{|l|}{ Glucose metabolic index } \\
\hline Fasting plasma glucose (mg/dl) & GLU0 & 1,138 & 80.625 & 7.755 & 869 & $130.700^{\mathrm{a}}$ & 47.400 \\
\hline $\begin{array}{l}\text { Plasma glucose after } 60 \mathrm{~min} \text { of oral } \\
\text { glucose tolerance test (OGTT) }(\mathrm{mg} / \mathrm{dl})\end{array}$ & GLU60 & 1,135 & 133.307 & 37.708 & 695 & $259.700^{\mathrm{a}}$ & 67.300 \\
\hline $\begin{array}{l}\text { Plasma glucose after } 120 \mathrm{~min} \text { of } \\
\text { OGTT (mg/dL) }\end{array}$ & GLU120 & 1,138 & 101.917 & 21.315 & 695 & $252.800^{\mathrm{a}}$ & 70.700 \\
\hline Fasting plasma insulin $(\mu \mathrm{U} / \mathrm{ml})$ & INSO & 1,138 & 7.459 & 6.754 & 872 & $8.580^{\mathrm{a}}$ & 5.990 \\
\hline $\begin{array}{l}\text { Plasma insulin after } 60 \mathrm{~min} \text { of } \\
\text { OGTT }(\mu \mathrm{U} / \mathrm{ml})\end{array}$ & INS60 & 1,135 & 33.320 & 31.813 & 692 & $24.100^{\mathrm{a}}$ & 26.300 \\
\hline $\begin{array}{l}\text { Plasma insulin after } 120 \mathrm{~min} \text { of } \\
\text { OGTT }(\mu \mathrm{U} / \mathrm{ml})\end{array}$ & INS120 & 1,138 & 23.436 & 24.317 & 692 & $30.000^{\mathrm{a}}$ & 36.500 \\
\hline Hemoglobin A1c (\%) & $\mathrm{HbA1c}$ & 1,138 & 5.486 & 0.241 & 1,122 & $7.530^{\mathrm{a}}$ & 1.740 \\
\hline $\begin{array}{l}\text { Homeostasis model assessment of } \\
\text { insulin resistance }\end{array}$ & HOMA-IR & 1,138 & 1.493 & 1.364 & 869 & 2.770 & 2.600 \\
\hline
\end{tabular}

${ }^{a}$ significant differences $(p<0.05)$ of variables between controls and cases were compared by student t-test for all variables except sex, which was compared by chi square test. 
Table 2. Logistic regression analysis of the association between 10 SNPs and T2DM, adjusted by age, sex, and BMI

\begin{tabular}{|c|c|c|c|c|c|c|}
\hline \multirow{2}{*}{ SNPs } & \multicolumn{2}{|c|}{ Codominant } & \multicolumn{2}{|c|}{ Dominant } & \multicolumn{2}{|c|}{ Recessive } \\
\hline & OR $(95 \% \mathrm{Cl})$ & $\mathrm{p}$ & OR $(95 \% \mathrm{Cl})$ & $p$ & OR $(95 \% \mathrm{Cl})$ & $\mathrm{p}$ \\
\hline \multicolumn{7}{|l|}{ SORBS1 } \\
\hline$-19147 \mathrm{C}>\mathrm{T}$ & $0.907(0.755 \sim 1.091)$ & 0.301 & $0.913(0.734 \sim 1.137)$ & 0.418 & $0.767(0.454 \sim 1.293)$ & 0.319 \\
\hline$-18485 \mathrm{G}>\mathrm{T}$ & $0.907(0.755 \sim 1.090)$ & 0.299 & $0.913(0.733 \sim 1.137)$ & 0.416 & $0.766(0.454 \sim 1.294)$ & 0.319 \\
\hline$+12922 C>A$ & $0.988(0.791 \sim 1.232)$ & 0.912 & $1.037(0.811 \sim 1.325)$ & 0.774 & $0.552(0.233 \sim 1.311)$ & 0.178 \\
\hline \multicolumn{7}{|l|}{$C B L$} \\
\hline$+69002 \mathrm{C}>\mathrm{T}$ & $1.048(0.901 \sim 1.219)$ & 0.545 & $1.088(0.864 \sim 1.370)$ & 0.472 & $1.032(0.791 \sim 1.346)$ & 0.817 \\
\hline$+71446 \mathrm{~T}>\mathrm{G}$ & $0.941(0.758 \sim 1.168)$ & 0.582 & $0.925(0.727 \sim 1.176)$ & 0.522 & $1.035(0.476 \sim 2.254)$ & 0.930 \\
\hline$+79066 \mathrm{C}>\mathrm{T}$ & $0.850(0.579 \sim 1.247)$ & 0.406 & $0.830(0.562 \sim 1.225)$ & 0.348 & N/A & $\mathrm{N} / \mathrm{A}$ \\
\hline \multicolumn{7}{|l|}{$R H O Q$} \\
\hline$-1617 C>A$ & $1.291(0.992 \sim 1.681)$ & 0.058 & $1.219(0.921 \sim 1.613)$ & 0.166 & $8.714(1.714 \sim 44.29)$ & 0.009 \\
\hline$-1601 G>A$ & $1.008(0.800 \sim 1.270)$ & 0.948 & $1.049(0.813 \sim 1.354)$ & 0.714 & $0.621(0.245 \sim 1.578)$ & 0.317 \\
\hline$-1510 \mathrm{~T}>\mathrm{C}$ & $1.095(0.937 \sim 1.279)$ & 0.254 & $1.061(0.859 \sim 1.310)$ & 0.582 & $1.299(0.935 \sim 1.806)$ & 0.119 \\
\hline$+751 \mathrm{G}>\mathrm{A}$ & $0.952(0.532 \sim 1.704)$ & 0.870 & $0.952(0.532 \sim 1.704)$ & 0.870 & N/A & $\mathrm{N} / \mathrm{A}$ \\
\hline
\end{tabular}

Underline indicates a significant result.

\section{Statistics}

To determine whether each individual variant was in equilibrium at each locus in the population (HardyWeinberg equilibrium), $\chi^{2}$ tests were applied. We examined the linkage disequilibrium (LD) coefficient, $\gamma^{2}$, between all pairs of biallelic loci (Hedrick and Kumar, 2001). Genotype frequencies were compared between patients and controls in 3 different modes (codominant, dominant, and recessive) by using logistic regression while controlling for age, sex, and BMI. Genotypes were given codes of 0,1 , and 2; 0,1 , and 1 ; and 0,0 , and 1 in the codominant, dominant, and recessive models, respectively. The SAS statistical software package (SAS Institute Inc. Cary, NC, USA) was used to perform general statistical analyses. Statistical significance was determined by a two-tailed value of $p<0.05$ for logistic regression.

\section{Results and Discussion}

To discover genetic variations in the tested genes, we sequenced all exons and their boundaries, including 1.5 $\mathrm{kb}$ upstream of the SORBS1, CBL, CRK, and TC10 genes, in the DNA samples of 24 unrelated Koreans. We identified 48 sequence variants (including 23 novel polymorphisms): 15 SNPs in the promoter region (1 SNP in CRK, 8 SNPs in SORBS1, and 6 SNPs in RHOQ), 1 SNP in the 5' UTR of $C B L, 2$ synonymous SNPs in coding sequences ( $1 \mathrm{SNP}$ in $C B L$ and $1 \mathrm{SNP}$ in $R H O Q$ ), 23 SNPs in introns (8 SNPs in CBL, 12 SNPs in SORBS1, and 3 SNPs in $R H O Q$ ), and 7 SNPs in the 3' UTR (3 SNPs in CRK and 4 SNPs in SORBS1) (see Supplementary Table 3). The locations of these poly- morphisms in relation to the genomic structures of each participant in the CAP/TC10 pathway are described in Supplementary Fig. 1.

Next, we selected 10 SNPs for larger-scale genotyping based on LDs, position, and frequencies $(>0.05)$. The SNP positions (marked with asterisks in Supplementary Fig. 1) from the translation start site are $-19147 \mathrm{C}>\mathrm{T}$ (rs3806202) in the promoter region of SORBS1; -18485G $>\mathrm{T}$ (rs4077664) in intron 1 of SORBS1; +12922C $>$ A (novel) in SORBS1 exon 13 of the 3' untranslated region (3' UTR); +69002C $>$ T (rs3794073) in intron 5 of $C B L ;+71446 \mathrm{~T}>\mathrm{G}$ (rs2510152) in intron 7 of $C B L ;+79066 \mathrm{C}>\mathrm{T}$ (rs227988) in exon 11 of $C B L ;-1617 C>A$ (rs1376405), $-1601 G>A$ (rs1868844), and $-1510 \mathrm{~T}>\mathrm{C}$ (rs3754554) in the promoter region of $R H O Q$; and $+751 \mathrm{G}>\mathrm{A}$ (novel) in exon 2. No deviation from Hardy-Weinberg equilibrium was observed in the genotype frequencies of the 10 SNPs in the 1138 nondiabetic controls.

Associations of the 10 SNPs with the risk of T2DM were analyzed using logistic regression, with adjustments for age, sex, and BMI as covariates. The results of the logistic regression analysis are described in Table 2. rs1376405, located in the promoter region of the $\mathrm{RHOQ}$ gene, had a risk for diabetes in the recessive mode, with an odds ratio of 8.714 (C.I. 1.714 44.29) and a $p$-value $=0.009$ in the comparison between nondiabetic controls and cases.

Overexpression of the RHOQ gene has been shown to inhibit insulin-stimulated GLUT4 translocation in adipocytes (Hou and Pessin, 2007). One hypothesis is that the genetic variation, rs1376405 in the promoter region of $R H O Q$, affects the expression level of TC10 protein, which in turn influences Glut4 translocation to the plas- 
ma membrane upon the insulin stimulus. As a result, the genetic variation of the $R H O Q$ gene could lead to the increased susceptibility to the development of type 2 diabetes mellitus in the Korean population. With further functional studies in row, the rs1376405 SNP in the $R H O Q$ locus could be exploited for the prediction of T2DM in the Korean population.

\section{Acknowledgments}

This study was supported by a grant of the Korea Healthcare technology R\&D Project, Ministry for Health, Welfare \& Family Affairs, Republic of Korea (A090318).

\section{References}

Baumann, C.A., Ribon, V., Kanzaki, M., Thurmond, D.C., Mora, S., Shigematsu, S., Bickel, P.E., Pessin, J.E., and Saltiel, A.R. (2000). CAP defines a second signalling pathway required for insulin-stimulated glucose transport. Nature 407, 202-207.

Chiang, S.H., Baumann, C.A., Kanzaki, M., Thurmond, D.C., Watson, R.T., Neudauer, C.L., Macara, I.G., Pessin, J.E., and Saltiel, A.R. (2001). Insulin-stimulated GLUT4 translocation requires the CAP-dependent activation of TC10. Nature 410, 944-948.

Gupte, A., and Mora, S. (2006). Activation of the CBL insulin signaling pathway in cardiac muscle; dysregulation in obesity and diabetes. Biochem. Biophys. Res. Commun. 342, 751-757.

Hedrick, P., and Kumar, S. (2001). Mutation and linkage disequilibrium in human mtDNA. Eur. J. Hum. Genet. 9, 969-972.

Hou, J.C., and Pessin, J.E. (2007). Ins (endocytosis) and outs (exocytosis) of GLUT4 trafficking. Curr Opin. Cell. Biol. 19, 466-473.

Hu, J., and Hubbard, S.R. (2005). Structural characterization of a novel CBL phosphotyrosine recognition motif in the APS family of adapter proteins. J. Biol. Chem. 280, 18943-18949.
Liu, J., Kimura, A., Baumann, C.A., and Saltiel, A.R. (2002). APS facilitates $C-C B L$ tyrosine phosphorylation and GLUT4 translocation in response to insulin in 3T3-L1 adipocytes. Mol. Cell. Biol. 22, 3599-3609.

Livak, K.J. (1999). Allelic discrimination using fluorogenic probes and the $5^{\prime}$ nuclease assay. Genet. Anal. 14, 143-149.

Noguchi, T., Matozaki, T., Inagaki, K., Tsuda, M., Fukunaga, K., Kitamura, Y., Kitamura, T., Shii, K., Yamanashi, Y., and Kasuga, M. (1999). Tyrosine phosphorylation of p62(Dok) induced by cell adhesion and insulin: possible role in cell migration. EMBO. J. 18, 1748-1760.

Park, K.S., Shin, H.D., Park, B.L., Cheong, H.S., Cho, Y.M., Lee, H.K. Lee, J.Y., Lee, J.K., Oh, B., and Kimm, K. (2006). Polymorphisms in the leptin receptor (LEPR)--putative association with obesity and T2DM. J. Hum. Genet. 51, 85-91.

Ribon, V., Herrera, R., Kay, B.K., and Saltiel, A.R. (1998). A role for CAP, a novel, multifunctional Src homology 3 domain-containing protein in formation of actin stress fibers and focal adhesions. J. Biol. Chem. 273, 4073-4080.

Ribon, V., Hubbell, S., Herrera, R., and Saltiel, A.R. (1996). The product of the CBL oncogene forms stable complexes in vivo with endogenous $\mathrm{CRK}$ in a tyrosine phosphorylation-dependent manner. Mol. Cell. Biol. 16, 45-52.

Ribon, V., and Saltiel, A.R. (1997). Insulin stimulates tyrosine phosphorylation of the proto-oncogene product of C-CBL in 3T3-L1 adipocytes. Biochem. J. 324(Pt 3), 839-845

Sasaoka, T., Rose, D.W., Jhun, B.H., Saltiel, A.R., Draznin, B., and Olefsky, J.M. (1994). Evidence for a functional role of Shc proteins in mitogenic signaling induced by insulin, insulin-like growth factor-1, and epidermal growth factor. J. Biol. Chem. 269, 13689-13694.

White, M.F., and Yenush, L. (1998). The IRS-signaling system: a network of docking proteins that mediate insulin and cytokine action. Curr. Top. Microbiol. Immunol. 228, 179-208.

Zierath, J.R., and Wallberg-Henriksson, H. (2002). From receptor to effector: insulin signal transduction in skeletal muscle from type II diabetic patients. Ann. N. Y. Acad. Sci. 967, 120-134. 